\title{
The Development of Mathematics Instruction Using Color Chips at Elementary School Based on Lesson Study
}

\author{
Fitrani Dwina, Riry Sriningsih \\ Mathematics Department, Faculty of Mathematics and Science \\ Universitas Nageri Padang \\ Padang, Indonesia \\ fitranidwina65@gmail.com
}

\begin{abstract}
This research aims to develop the mathematics instruction using color chips at elementary school based on Lesson Study. This research was conducted at fifth grade of State Elementary School 23, Padang Timur. The development is adapted from Plomp's model. There are three phases of the development: preliminary research, development/prototype phase, and assessment phases. This research is focused on development/prototyping. The first step of the research is to distribute questionnaires to three teachers for the sake of getting some information about the problems in mathematics instruction at the school. The problem is that the teachers still have the difficulties in showing the real process of addition and subtraction operations on the integers. The second step is to prepare the color chips and create the booklet about the use of color chips. In this prototyping phase the booklet is corrected by the teacher and expert. This phase had micro-cycle until the teacher and the students find the booklet useful. In the first prototype, validation is conducted by self evaluation and expert's review. After the revision of the first prototype, the second prototype is created, and then it is used to know its practicality through implementation in small group evaluation.
\end{abstract}

Keywords-Booklet, Color Chips, Elementary School, Lesson Study

\section{INTRODUCTION}

This paper describes how color chips can be used to help teacher to show the real process of addition and subtraction operation on the integers. Mathematics is one of the subjects studied at Elementary School. Students at Elementary School are around 7-11 years old. They start thinking on logic of Mathematics. Piaget said that student logically thinks based on manipulation of an object [1]. For the purpose of this study, teacher can use booklet and color chips to teach student in real situation. Students can used color chips to understand about the real process in addition and subtraction operations on the integers.

Based on the regulation of Minister of Education and Culture, mathematics instruction is started from the real situation (contextual problem). The term manipulative is defined as item that students use to support hands-on learning [2]. Color chips provide visible models that help students solve problems and develop concepts.

In recent years, especially in Mathematics, many parties have questioned whether manupilatives are beneficial and some have suggested that manipulatives are over-rated as a teaching resource [2]. Manipulatives can range from paper and plastic. Manipulative materials are objects designed to represent explicitly and concretely the abstract mathematical ideas. They have both visual and tactile appeals and can be manipulated by learners trough hands-on expriences [3]. Research suggests that manipulatives can help students develop mathematical concept in a concrete and visual form for the learner [4]. Lesson study is an activity that can improve the instruction quality.

Lesson study (or kenkyu jugyo) is a teaching improvement process originating from Japanese elementary education, where it is a widespread professional development practice. Working in a small group teachers collaborate with one another, meet to discuss learning goals, plan an actual classroom lesson (called a research lesson), observe how it works in practice, and then revise and report on the results, so that other teachers can get benefit from it [5]. Participants share their observations and examine additional evidence from the lesson, such as students' written work, searching for pattern revealing important insight in teaching practice and student learning [6].

\section{METHODS}

The development is adapted from Plomp's model. The procedure is to develop the useful booklet for teacher and students to describe and understand about the real process of addition and subtraction operations on the integers. It covers preliminary research and development/prototype phase. At the step of preliminary research, the researcher distributes questionnaires to three teachers to get some information about the problems in mathematics instruction at the fifth grade. The problem is that the teachers still have the difficulties how to show the real process of addition and subtraction operation on 
the integers. The second step to prepare the color chips and create the booklet about the use of color chips. This research is conducted at fifth grade of an state elementary school 23 in Padang Timur.

\section{RESULT}

The development of booklet has two phases; these are preliminary and prototiping phases. There are three main steps in preliminary phase: structure analysis, concept analysis and teacher need analysis. The structure analysis focus based on cognitive, affective and psychomotor indicator. The concept analysis focused on addition and subtraction operation at integer. The second step was preparing the color chips and creating the booklet about how to use color chips. In this prototyping phase the booklet was corrected by teacher and expert. This phase had micro-cycle until the teacher and the students find the booklet useful. In first prototype, validation was conducted by self evaluation and expert review. After the revision of the first prototype, the second prototype was created, and then it was used to know about its practicality by implementation in small group evaluation.

In the first prototype, booklet have been revised based on result validation from mathematics and language experts.

TABLE 1: Result BoOKLet VALIDATION FOR USING COLOR CHIPS FROM EXPERT

\begin{tabular}{|c|c|l|c|c|}
\hline No & Expert & Evaluation & $\begin{array}{c}\text { Validity } \\
(\%)\end{array}$ & Category \\
\hline 1 & \multirow{2}{*}{ Mathematics } & Content & 95.50 & Very valid \\
\cline { 3 - 5 } & & Language & 85 & Very valid \\
\cline { 3 - 5 } & & Presentation & 87 & Very valid \\
\cline { 3 - 5 } & & Picture & 93.75 & Very valid \\
\hline 2 & Language & Sentence & 90.25 & Very valid \\
\hline
\end{tabular}

The second prototype was created based on self evaluation and expert's validation, and then it was used to know about its practicality by its implementation in small group evaluation. The try out for practicality have been done to six students at fifth grade at elementary school. They are two students in higher level, two students in middle level, and two students in lower level.

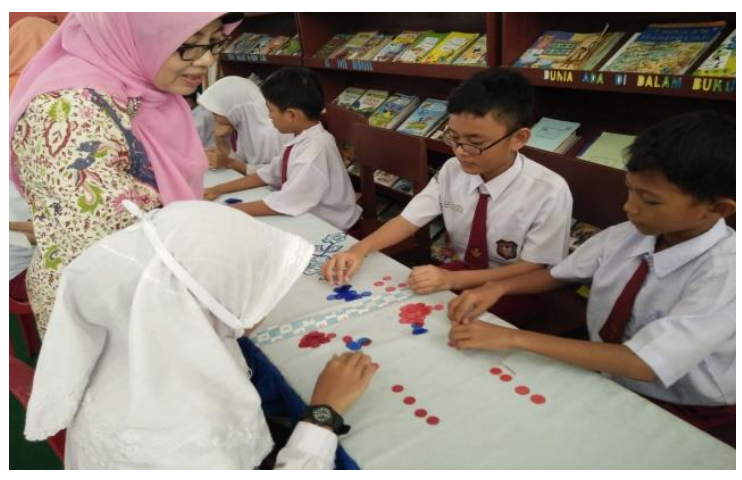

Figure 1. Students practice using color chips
Based on observation since the students has practiced, they look very interested and happy done the problems for addition and subtraction operation at the integers.

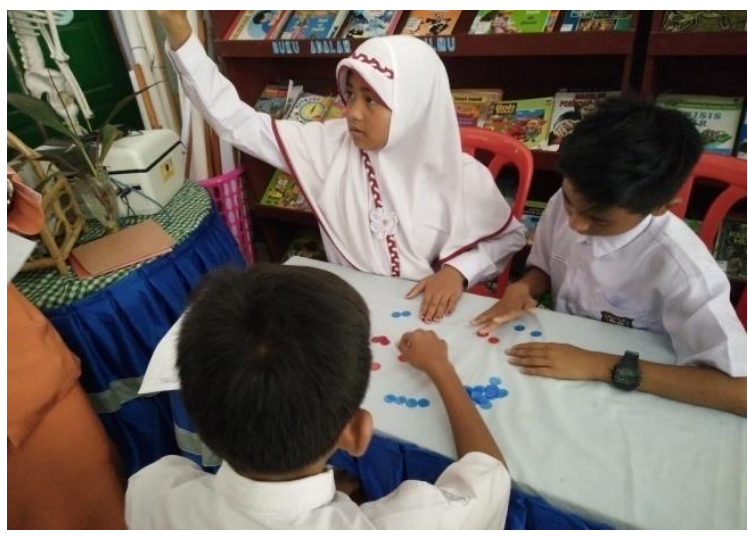

Figure 2. Students' expression when using color chips

After small group evaluation, a questionnaire is given to the teacher about the practicality of booklet to practice using color chips.

\begin{tabular}{|c|l|c|c|}
\hline No & \multicolumn{1}{|c|}{ Aspect } & $\begin{array}{c}\text { Practicality } \\
(\%)\end{array}$ & Category \\
\hline 1 & Usefulness & 95 & Very practical \\
\hline 2 & Benefit & 95 & Very practical \\
\hline 3 & $\begin{array}{l}\text { Time } \\
\text { appropriateness }\end{array}$ & 75 & Very practical \\
\hline
\end{tabular}

The teachers involved give the various reasons for using manipulatives. One of these is that the use of manipulatives is more enjoyable than when doing soley mathematics, both abstract and symbolic one. This is substantiated by the teachers's observation showing that the students were active, engaged and interested in lessons when manipulatives were used.

\section{DISCUSSION}

$\mathrm{n}$ operations of addition and subtraction on the integers, color chips can be used to show the real situation. Before using the color chipss, we have to agree with the regulation that red color is for negative numbers and blur color is for positive numbers.

Symbol for positive numbers

Symbol for negative numbers

Means -2

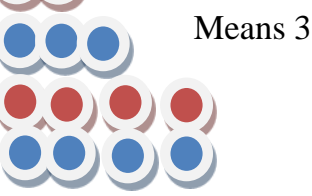

If the red and blue chips have the same numbers (as a couple), these can be called zero. 
The addition and subtraction on the integers can be shown some examples bellow:

1) $2+(-3)=\ldots$.

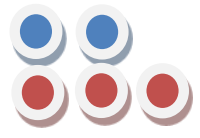

To find the answer of combining the red color and the blue color, two couple of the red and the blue become zero, and reminder is one red color, so the result for $2+(-3)=-1$.

2) $q 3-(-2)=\ldots \ldots$

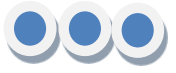

There are three blue chips. Two red chips are taken away; we do not have red chips. In this process it has to be added zero (couples of red and blue chips),

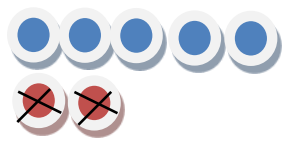

we can take away $(-2)$, so the result is $3-(-2)=5$.

3) $(-3)-4=\ldots$

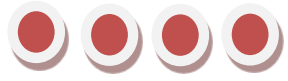

There are three red chips. Four blue chips are taken away; we do not have blue chips. To solve the problem, it has to be added zero ( couples of red and blue chips),

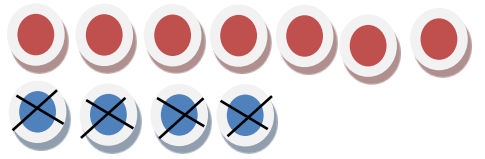

Now we can take away 4 , so the result is $(-3)-4=(-7)$.

In addition and subtraction of the integers, we have to explain that addition means compounding and subtraction means taking away. Students are enjoying and glad when doing mathematics using color chips.

The teachers have to give more exercises for students to make them understand more about the concept in addition and subtraction operations on the integers. To motivate teachers and students, lesson study can be implemented. Attitude toward mathematics can infleunce the quality of learning [7].

\section{CONCLUSIONS}

The use of color chips and booklet in mathematics instruction especially for addition and abstraction operations on the integers gives some advantages. That is to say that manipulative can be powerful means to support sense making. Mathematical thinking and reasoning when used as a means to support the process rather than as adjuncts to blindly follow a teaching procedure to find answers. Lesson study is a strategy that can be used in mathematics instruction.

\section{ACKNOWLEDGMENT}

I would like to say thank you for all people who help and give me a chance to do my research. Thank you for the director of research and public services for funding my research. The teacher and students at elementary public school no 23 Padang Timur and also my research team. I can't tell one by one to any body who company with me in this activity.

\section{REFERENCES}

[1] H. Hudojo. Learning Theory in Mathematics Teaching. Jakarta: Dikti P2LPTK, 1984.

[2] C. Ashlee and W. K. Peter, "Mathematical manipulative: creating an environment for understanding, efficiency, engagement, and enjoyment," in Teach Collection of Christian Education, vol I, 2015, pp.47-54.

[3] J. Back, "Manipulative in The Primary Classroom", nrich University of Cambrige .

[4] F. Dwina, "Manipulative tool in mathematics instruction at elememtary school", in Instruction journal, vol 29, 2006, pp. 67-78.

[5] Wikipedia an encyclopedia

[6] W. Cerbin and B. Kopp, "Lesson Study as a Model for Building Pedagogical Knowledge and Improving Teaching," International Journal of Teaching and Learning in Higher Education, 18(3), 2006, 250-257.

[7] M. Zorofi, "The Study of Students' Mathematics Lesson Learning Quality”, ICMER 2010, pp 205-211. 